\title{
The effect of climate change on extreme waves in front of the Dutch coast
}

\author{
Renske C. de Winter • Andreas Sterl • \\ Johannes W. de Vries • Susanne L. Weber • \\ Gerben Ruessink
}

Received: 9 December 2011 / Accepted: 8 May 2012 / Published online: 10 June 2012

(C) The Author(s) 2012. This article is published with open access at Springerlink.com

\begin{abstract}
Coastal safety may be influenced by climate change, as changes in wave conditions (height, period, direction) may increase the vulnerability of dunes and other coastal defences. Dune erosion depends on mean water level, storm surge height and wave conditions. In this paper, we investigate the change in wave conditions in the North Sea in a changing climate. Until now, the effect of climate change on annual maximum wave conditions has been investigated, while events with higher return periods are actually most damaging for the coast (e.g. severe dune erosion). Here, we use the 17-member Ensemble SimulationS of Extreme weather under Nonlinear Climate changeE (ESSENCE) change of climate change simulations, to analyse A1b-induced changes in the mean wave climate, the annual maxima and wave conditions with return periods of up to $1: 10,000$ years in front of the Dutch coast. The mean wave climate is not projected to differ between 1961-1990 and 20712100 , with both wave height $\left(H_{\mathrm{s}}\right)$ and wave period $\left(T_{\mathrm{m}}\right)$ remaining unaltered. In the annual maximum conditions, a decrease is projected; especially, the annual $T_{\mathrm{m}}$ maximum decreases significantly by 0.3 to $0.6 \mathrm{~s}$ over
\end{abstract}

Responsible Editor: Birgit Andrea Klein

S. L. Weber, deceased 12 August 2011.

R. C. de Winter $(\bowtie)$ · S. L. Weber · B. G. Ruessink Department of Physical Geography, Faculty of Geosciences, Institute for Marine and Atmospheric Research, Utrecht University, P.O. Box 80.115,

3508 TC Utrecht, Netherlands

e-mail: r.c.dewinter@uu.nl

R. C. de Winter · A. Sterl · J. W. de Vries · S. L. Weber Royal Netherlands Meteorological Institute (KNMI), P.O. Box 201, 3730 AE De Bilt, Netherlands the whole study area. Furthermore, we find that the direction of the annual maximum wave conditions shifts from north and north-west to west and south-west for both $H_{\mathrm{s}}$ and $T_{\mathrm{m}}$. This is induced by a similar shift in the direction of the extreme wind speeds. Despite the decrease in annual maximum conditions, the return $H_{\mathrm{s}}$ and $T_{\mathrm{m}}$ are not projected to change significantly as a result of climate change in front of the Dutch coast for the period 2071-2100 relative to 1961-1990.

Keywords Climate change $\cdot$ Waves Extremes . North Sea

\section{Introduction}

Climate change may affect the hydrodynamic conditions at many coasts. For coastal defences, such as dunes or sea dikes, the possible change in the hydrodynamic boundary conditions may aggravate the situation at defences that are already under attack during extreme sea states or may cause defences that are now considered to be sufficiently safe to be judged as unsafe. Traditionally, accelerated sea level rise has been considered as the major climate-change effect on coastal systems (e.g. Bruun 1962; Vellinga and Leatherman 1989; Zhang et al. 2004; FitzGerald et al. 2008; Nicholls and Cazenave 2010), but for many coasts, changes in wave and surge conditions are potentially more important.

As pointed out by Bindoff et al. (2007), modelling frameworks to translate results of global climatechange simulations to local coastal studies are in their infancy. This paper is motivated by our desire to examine the possible effect of climate change on dune 
erosion, with a focus on the Dutch coast. This densely populated, low-lying area is protected by relatively narrow dunes. The February 1953 storm, during which the dune foot retreated by 10-20 $\mathrm{m}$ along large parts of the Dutch coast (e.g. Ruessink and Jeuken 2002), resulted in a coastal policy in which the safety of the dunes to withstand an event with a 1:10,000 probability is assessed every 4-6 years (Kabat et al. 2009). Laboratory experiments (e.g. Van de Graaff 1977; Vellinga 1982; Coeveld et al. 2005; Van Gent et al. 2008) and model simulations (e.g. Vellinga 1983; Steetzel 2002; Van Rijn 2009) show that the amount of dune erosion is primarily determined by the storm surge level, the offshore wave height $\left(H_{\mathrm{s}}\right)$, the peak wave period $\left(T_{\mathrm{p}}\right)$, the wave angle $(\theta)$ and the characteristics of the dune itself, such as bed material size and beach profile. The model calculations of Van Rijn (2009) show that higher surge levels, $H_{\mathrm{s}}$ and $T_{\mathrm{p}}$ result in substantial larger volumes of eroded sand. According to his simulations, dune erosion also increases for wave angles in the range of $0^{\circ}-10^{\circ}$ with respect to the shore normal, while for larger angles of incidence, the erosion was found to remain more or less constant even though the aforementioned dune-erosion models range from purely empirical (e.g. Van Gent et al. 2008; Den Heijer et al. 2012) to more processbased (e.g. Roelvink et al. 2009; Van Rijn 2009). All these models have offshore wave characteristics as an input. For example, the Duros+ model (Den Heijer et al. 2012), presently applied in Dutch coastal policy, uses $H_{\mathrm{s}}$ and $T_{\mathrm{p}}$ at the $-20-\mathrm{m}$ depth contour as an input. The aim of this paper is, therefore, to analyse the effect of climate change on the offshore wave conditions in front of the Dutch coast. The results of this paper will be used in future work as the seaward wave-boundary conditions for a nearshore dune-erosion model.

Previous studies on climate-change effect on $H_{\mathrm{s}}$ in the North Sea (e.g. Grabemann and Weisse 2008; Debernard and Røed 2008; Lowe et al. 2009) indicate small but statistically significant increases in $H_{\mathrm{s}}$ along the Dutch-German coast, with magnitudes depending on the particular general circulation model (GCM) or regional climate model (RCM) and the emission scenarios applied. For example, using the HadAM3H and the ECHAM4/OPYC3 GCM with scenarios A2 and B2, Grabemann and Weisse (2008) found a 0.1$0.3-\mathrm{m}$ increase in the 99th percentile of $H_{\mathrm{s}}$ in front of the Dutch coast. Debernard and Røed (2008) came to a comparable result of an increase by $2-4 \%$ of the 99th percentile $H_{\mathrm{s}}$, using several GCMs and SRES scenarios: HADAM3H(A2 and B2), ECHAM4 (B2) and BCM (A1b). Furthermore, they found a tendency for the largest events to be higher in the future climate. Both Grabemann and Weisse (2008) and Debernard and Røed (2008) found that the difference between two models forced with the same emission scenario is larger than the difference between one model forced with two different emission scenarios. The effect of scenario choice has limited influence on the change in $H_{\mathrm{s}}$. However, both studies found for all models and scenarios an increase in the 99th percentile of $H_{\mathrm{s}}$ in the eastern North Sea (German Bight). Following the SRES A1b scenario, Lowe et al. (2009) projected the annual $H_{\mathrm{s}}$ maxima to change between 0 and $0.5 \mathrm{~m}$ at the 95th percentile significant level in the south-eastern North Sea using the GCM HadCM3 and the RCM HadRM3 (Lowe et al. 2009, their Fig. 5.10).

Analysing changes in a changing climate implies that several uncertainties need to be taken into account. First, the uncertainty in the climate scenarios, which provide the possible development of the emission of greenhouse gasses. Second, there is uncertainty in the climate models that are used to analyse the effect of different emission scenarios. As mentioned above, for $H_{\mathrm{s}}$, the model uncertainty appears to be larger than scenario uncertainty. The third uncertainty is the internal variability of the climate. The natural variability of a system might be large which can be a difficulty when analysing trends that are smaller than this natural variability. The internal variability results in statistical uncertainty, especially for events with high return values. The studies of Grabemann and Weisse (2008) and Debernard and Røed (2008) were based on a few transient climate simulations of (parts of) the twentyfirst century, due to the high computational demand of a single simulation. The resulting time series are too short to accurately assess return levels of waves that are sufficiently intense to result in major damage to dunes. The aforementioned 99th percentile, for example, implies wave conditions that happen on 3-4 days each year. For dune erosion, we should look at events with 1:1- to 1:10-year return value (Ruessink and Jeuken 2002; Quartel et al. 2008) or even smaller, such as the 1:10,000-year value prescribed in Dutch coastal policy.

The work presented here is based on a large ensemble of model runs, enabling to reduce the impact of the internal variability on the uncertainty. As a consequence, we are able to analyse events with return periods of 10 years and higher with reasonably small error bands. We use 3-hourly data from the 17-member Ensemble SimulationS of Extreme weather under Nonlinear Climate changeE (ESSENCE) (Sterl et al. 2008), based on the ECHAM5/MPI-OM climate model and the SRES A1b emission scenario. The 3-hourly data ensure that storm events that impact dune erosion are resolved in our study using the ESSENCE ensemble. Although Sterl et al. (2009) found little change in North 
Sea wind climate, they noticed an increase in wind speeds above 8 Beaufort force $(\mathrm{Bf})(17 \mathrm{~m} / \mathrm{s})$. These winds tend to come less often from the north and northwest and more often from west and south-west. We are interested in the effect of this change on extreme waves on the open North Sea as boundary conditions for dune-erosion models.

\section{Methodology}

\subsection{Models}

Two models were used to determine the change in the wave climate at the Dutch coast, a GCM and a wave model. The climate simulation used for this research is the ESSENCE ensemble (Sterl et al. 2008), which uses the coupled climate model ECHAM5/MPI-OM (Jungclaus et al. 2006). The ESSENCE ensemble consists of 17 runs that cover from 1950 to 2100. Small perturbations in the initial conditions ensure that every ensemble member evolves differently. The greenhouse gas forcing follows the SRES A1b scenario in all members. The output data used to force the wave model have a temporal resolution of $3 \mathrm{~h}$ and a spatial resolution of $2 \times 2^{\circ}$.

The wave fields were generated with NEDWAM, ${ }^{1}$ a regional version of the third-generation global WAve prediction Model WAM (Mastenbroek et al. 1993; Komen et al. 1994). The Royal Netherlands Meteorological Institute (KNMI) uses NEDWAM as its operational model for wave predictions in the North Sea area (Fig. 1). The special resolution is $1 / 2^{\circ}$ west-east and $1 / 3^{\circ}$ north-south, approximately $32 \mathrm{~km}$ for both directions. Twenty-five frequencies are defined, starting at $0.0417728 \mathrm{~Hz}$ and increasing by $10 \%$ for every next frequency. The directional spectral resolution is $30^{\circ}$ at each frequency. NEDWAM predicts directional spectra as well as frequency- and direction-integrated wave parameters, such as $H_{\mathrm{s}}, T_{\mathrm{m}}$ and $\theta$. In NEDWAM, $H_{\mathrm{s}}$ is defined as $H_{\mathrm{s}}=4 \sqrt{m_{0}}$ and the significant wave period $\left(T_{\mathrm{m}}\right)$ is defined as $T_{m 0,-1}=\left(\frac{m_{0}}{m_{1}}\right)^{-1}$, where $m_{n}$ is the $n$th spectral moment. $\theta$ is the mean wave direction and defined as 'coming from', with respect to the true north (Burgers 1990). The operational NEDWAM model is forced with the weather forecast model HIRLAM. ${ }^{2}$ For our research, the wind and sea level pressure outputs from the ESSENCE ensemble were used as forcing.

\footnotetext{
${ }_{1}^{1}$ http://www.knmi.nl/research/maritime_modelling/nedwam

${ }^{2}$ www.hirlam.org
}

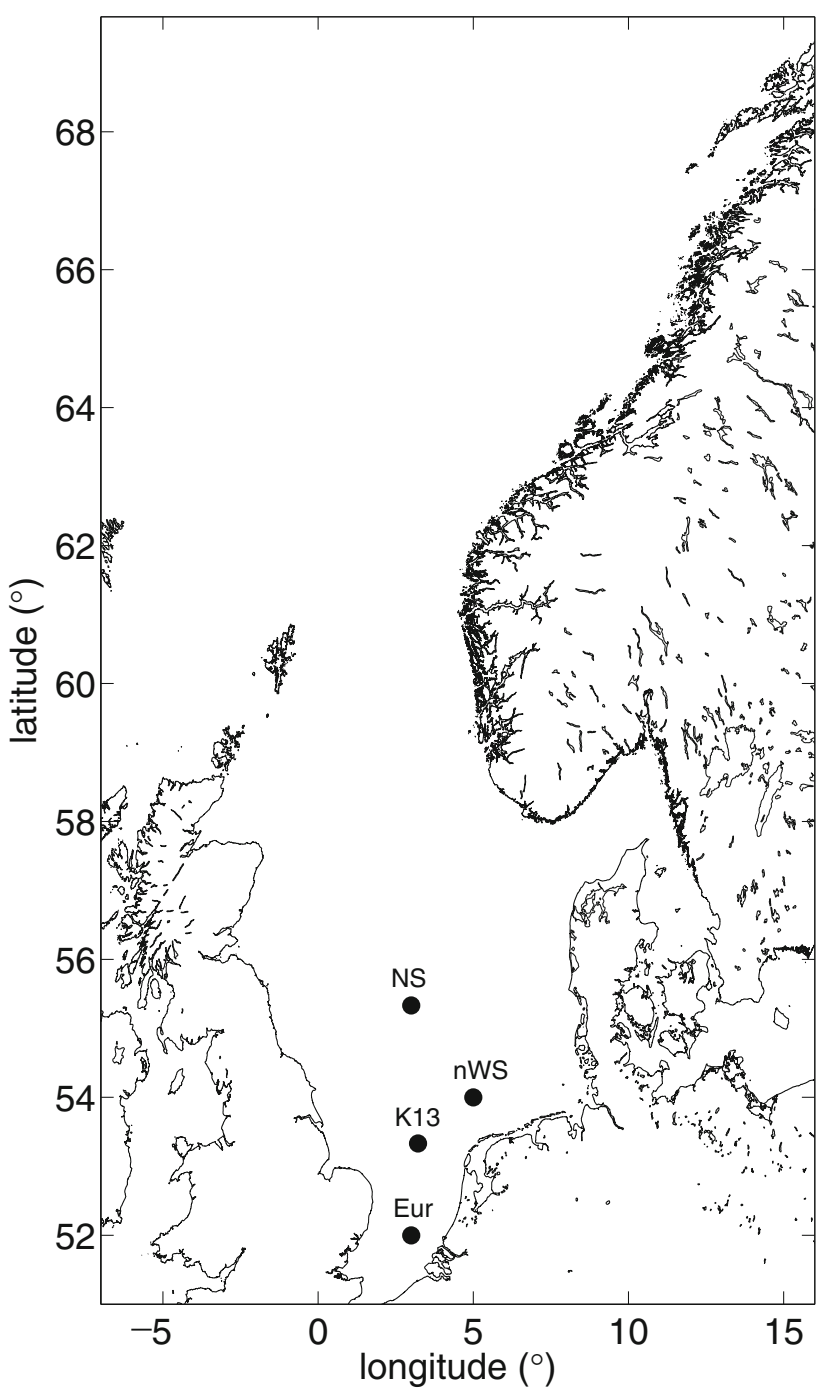

Fig. 1 NEDWAM domain, from $7^{\circ} \mathrm{W}$ to $16^{\circ} \mathrm{E}$ and $51^{\circ} \mathrm{N}$ to $69^{\circ} 40^{\prime} \mathrm{N}$, grid spacing $30^{\prime} \mathrm{S}-\mathrm{N}$ and $20^{\prime} \mathrm{W}-\mathrm{E}$; four locations are marked, K13, Euro platform (Eur), $n W S$ and $N S$

\subsection{NEDWAM performance}

Before we use the ESSENCE-NEDWAM combination to study sea states in a future climate, we first need to assess the accuracy of NEDWAM. This was performed by comparing the operational forecast for wind and waves with the observed wind and wave parameters for the period 2004-2009. This analysis was done for two offshore locations in the North Sea for which measured and operationally forecasted data were available: K13 and Euro platform (Eur) (Fig. 1) (data available via KNMI). The data used have a resolution of $6 \mathrm{~h}$. Differences between observed and forecasted wave parameters cannot be due to the NEDWAM model and can also result from inaccuracies in HIRLAM's wind and sea level pressure fields. 

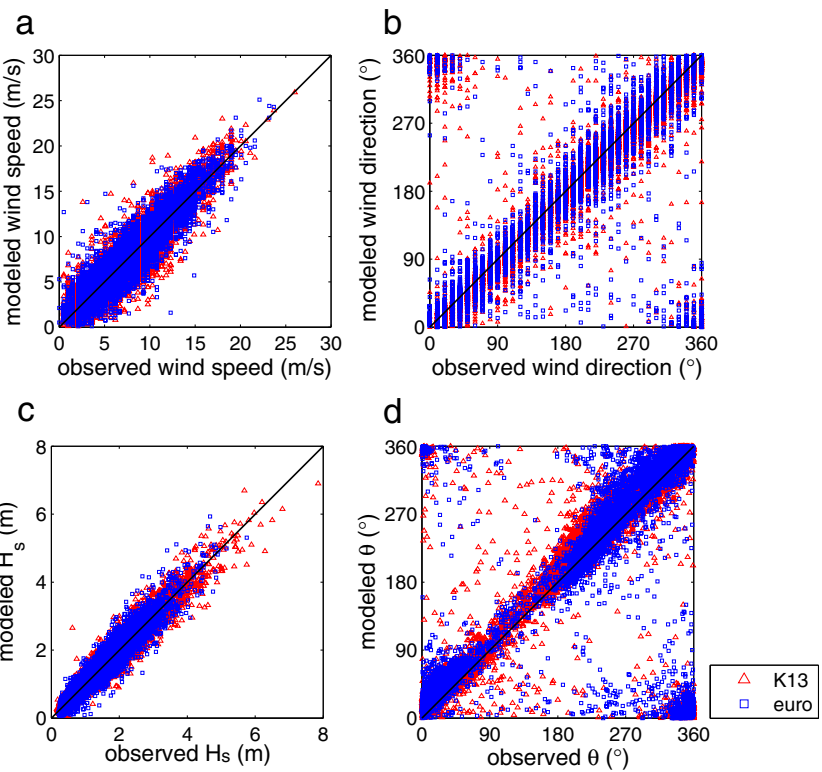

Fig. 2 For locations K13 and Eur, modelled versus observed data. a Wind speed, b wind direction, $\mathbf{c} H_{\mathrm{S}}$ and $\mathbf{d} \theta$, skill is given in Table 1 . The discontinuity of angles at $0^{\circ}\left(360^{\circ}=0^{\circ}\right)$ leads to the values in the top left and bottom right corner in $\mathbf{b}$ and $\mathbf{d}$

Figure $2 \mathrm{a}, \mathrm{b}$ and Table 1 demonstrate that HIRLAM-predicted wind speeds and directions agree well with the observations at K13 and Eur, as expressed by the high correlation coefficient squared $r^{2}$, a slope $m$ of the best-fit linear line of nearly one and a rootmean-square error (RMSE) of 1.48 and $1.55 \mathrm{~m} / \mathrm{s} . H_{\mathrm{s}}$ is predicted well with negligible bias $(\mathrm{m} \approx 1)$ at both K13 and Eur. The wave direction forecasts are less accurate (Table 1). The relation between the forecasted and observed wave direction is also depicted in Fig. 5 (central plot), showing that the overall pattern of waves coming from the dominant directions, north-west and south-west, is the same in the observed and forecasted data set.

Wave models often have problems with predicting wave extremes (Cavaleri 2009). The period for which

Table 1 Skill of observations versus operational forecast

\begin{tabular}{lllc}
\hline & $r^{2}$ & $m \pm 95 \%$ range & RMSE \\
\hline K13 & & & \\
$\quad$ Wind speed & 0.77 & $0.90 \pm 0.011$ & 1.55 \\
Wind direction & 0.61 & $0.76 \pm 0.014$ & 63.5 \\
$H_{\mathrm{s}}$ & 0.94 & $0.97 \pm 0.005$ & 0.21 \\
$5 \%$ highest $H_{\mathrm{S}}$ & 0.68 & $0.86 \pm 0.058$ & 0.41 \\
$\theta$ & 0.41 & & 99.8 \\
& & & \\
Eur & 0.86 & $0.95 \pm 0.009$ & 1.48 \\
Wind speed & 0.61 & $0.80 \pm 0.0145$ & 65.6 \\
Wind direction & 0.93 & $1.00 \pm 0.006$ & 0.21 \\
$H_{\mathrm{s}}$ & 0.61 & $0.99 \pm 0.077$ & 0.41 \\
$5 \%$ highest $H_{\mathrm{s}}$ & 0.41 & & 119.9 \\
$\theta$ & & & \\
\hline
\end{tabular}

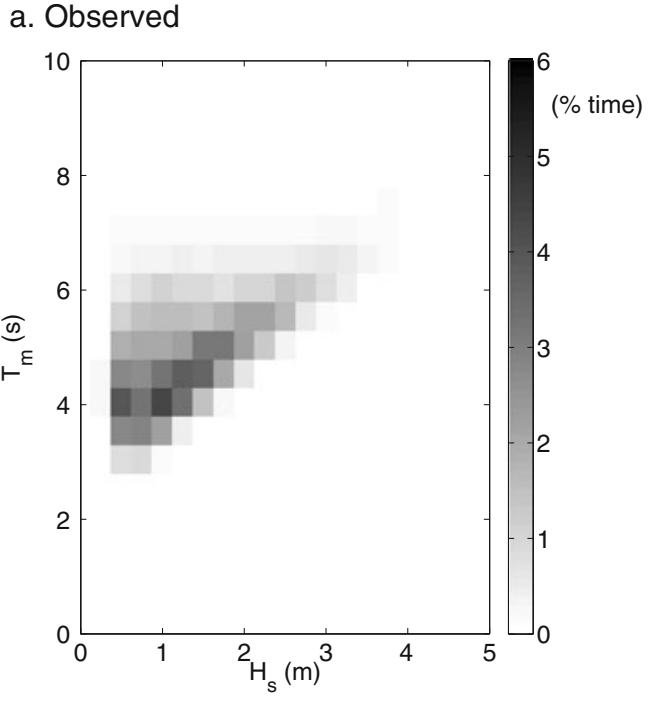

b. ESSENCE-NEDWAM

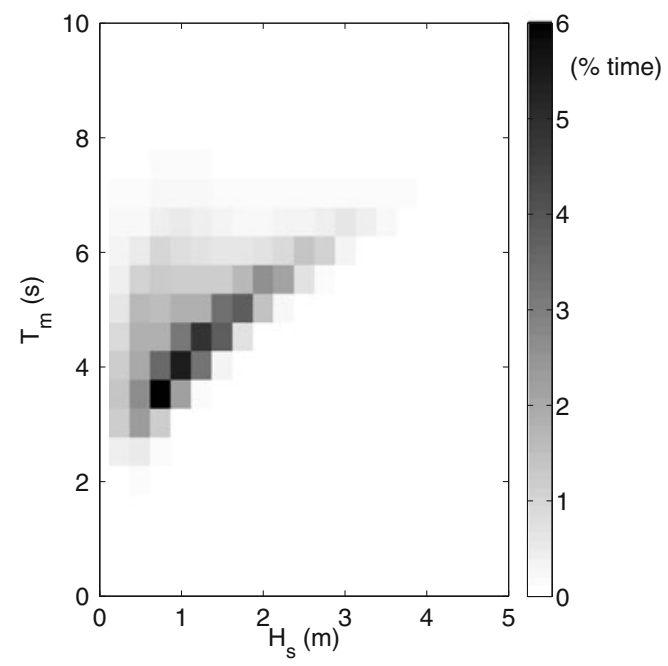

Fig. 3 a For the observed waves, the relation between $H_{\mathrm{s}}$ and $T_{\mathrm{m}}$ as percentage of time at Eur. b Same as a for the ESSENCENEDWAM climatology

the wave forecast can be compared with observed wave parameters is limited to 6 years (2004-2009). It is therefore only possible to investigate extreme events to a limited extent. The 5\% highest observed waves range from 3.3 to $7.85 \mathrm{~m}$ for $\mathrm{K} 13$ and from 2.77 to $5.75 \mathrm{~m}$ for Eur. The $5 \%$ highest observed waves are compared with the corresponding wave height (at the same time) from the operational forecast. Table 1 demonstrates that these moderate extremes were forecasted correctly or were slightly underestimated.

\subsection{ESSENCE-NEDWAM performance}

To access the performance of NEDWAM when forced with ESSENCE model data, we compare observations and the operational forecast from 2004 to 2009 with 17 

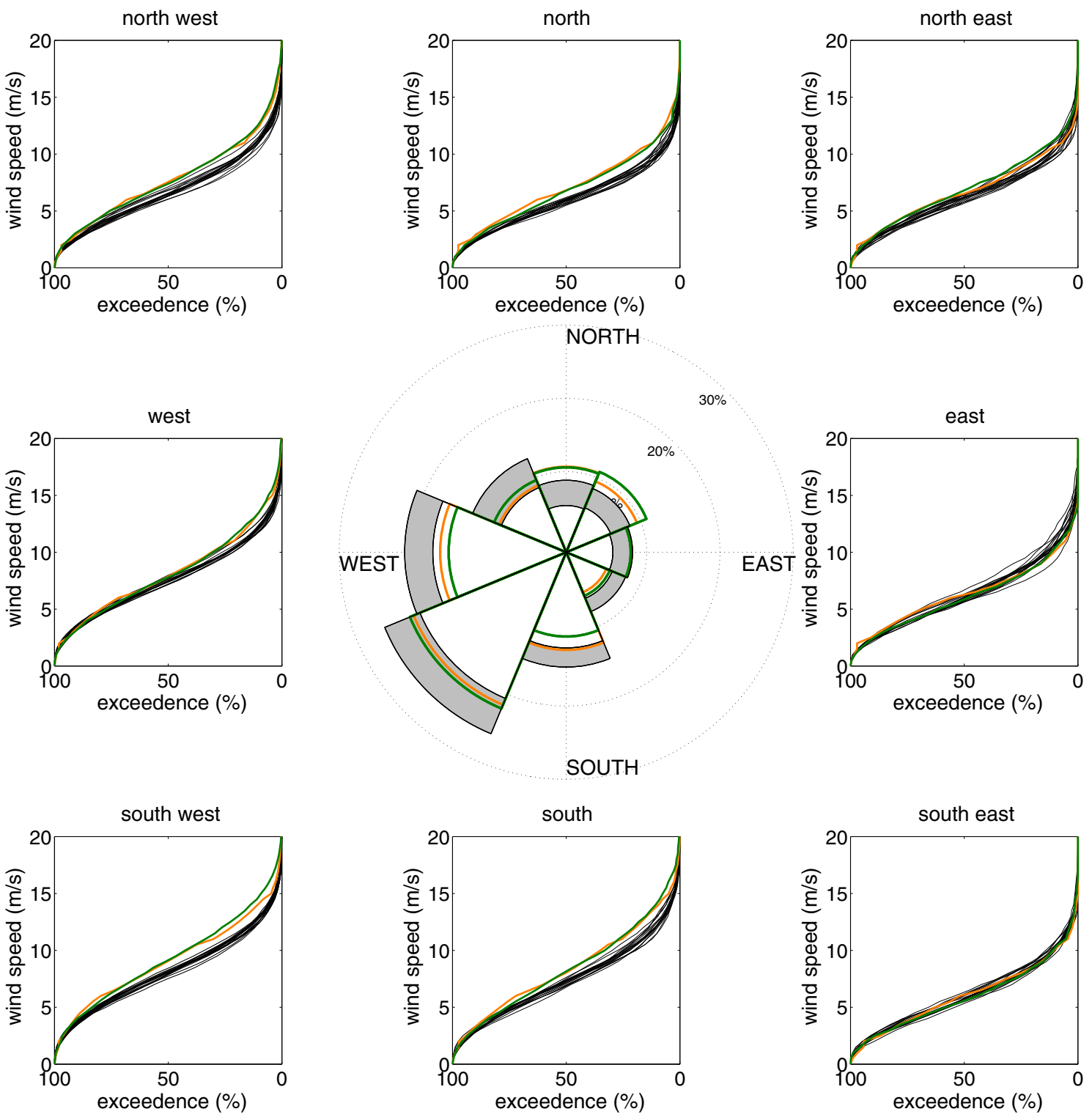

Fig. 4 The central plot shows the frequency of wind for $45^{\circ}$ wide direction classes at Eur for the period 2004-2009. Orange represents the observed directions and green represents the operational forecasted direction for HIRLAM. In grey, the bandwidth

NEDWAM calculations forced with ESSENCE members. If the wave climate of the observed and operational forecasted data is within the climate variability of the 17-member ESSENCE-NEDWAM calculations, we may state that the ESSENCE-NEDWAM combination is capable of statistically regenerating the wave climate and that it can be used for climate change analysis of the wave climate on the North Sea. We chose to run ESSENCE-NEDWAM also over a 6-year time period, to reliably compare moderate extremes. Furthermore, the climatological conditions should be the same; therefore, the same 6-year period for which we have observations was used. of percentage of wind of the 17 ESSENCE runs is depicted. The surrounding plots show $H_{\mathrm{s}}$ exceedence curves for all eight directions classes. Colours are the same as for the central plot, and all the 17 ESSENCE runs are plotted individually in black

The $H_{\mathrm{s}}-T_{\mathrm{m}}$ relation in the ESSENCE-NEDWAM climatology has a similar distribution as the $H_{\mathrm{s}}-T_{\mathrm{m}}$ relation of the observed waves (Fig. 3), indicating that the $H_{\mathrm{s}}-T_{\mathrm{m}}$ relation in the ESSENCE-NEDWAM combination is realistic. The wind rose (central plot of Fig. 4) shows that, in general, the climate variability of the ESSENCE ensemble overlaps with the observed wind directions; however, the amount of wind from the north and north-east is slightly underestimated. For most directions, the wind speed is slightly underestimated in the ESSENCE ensemble (surrounding plots of Fig. 4) . The underestimation of winds from the north possibly causes the underestimation of the 

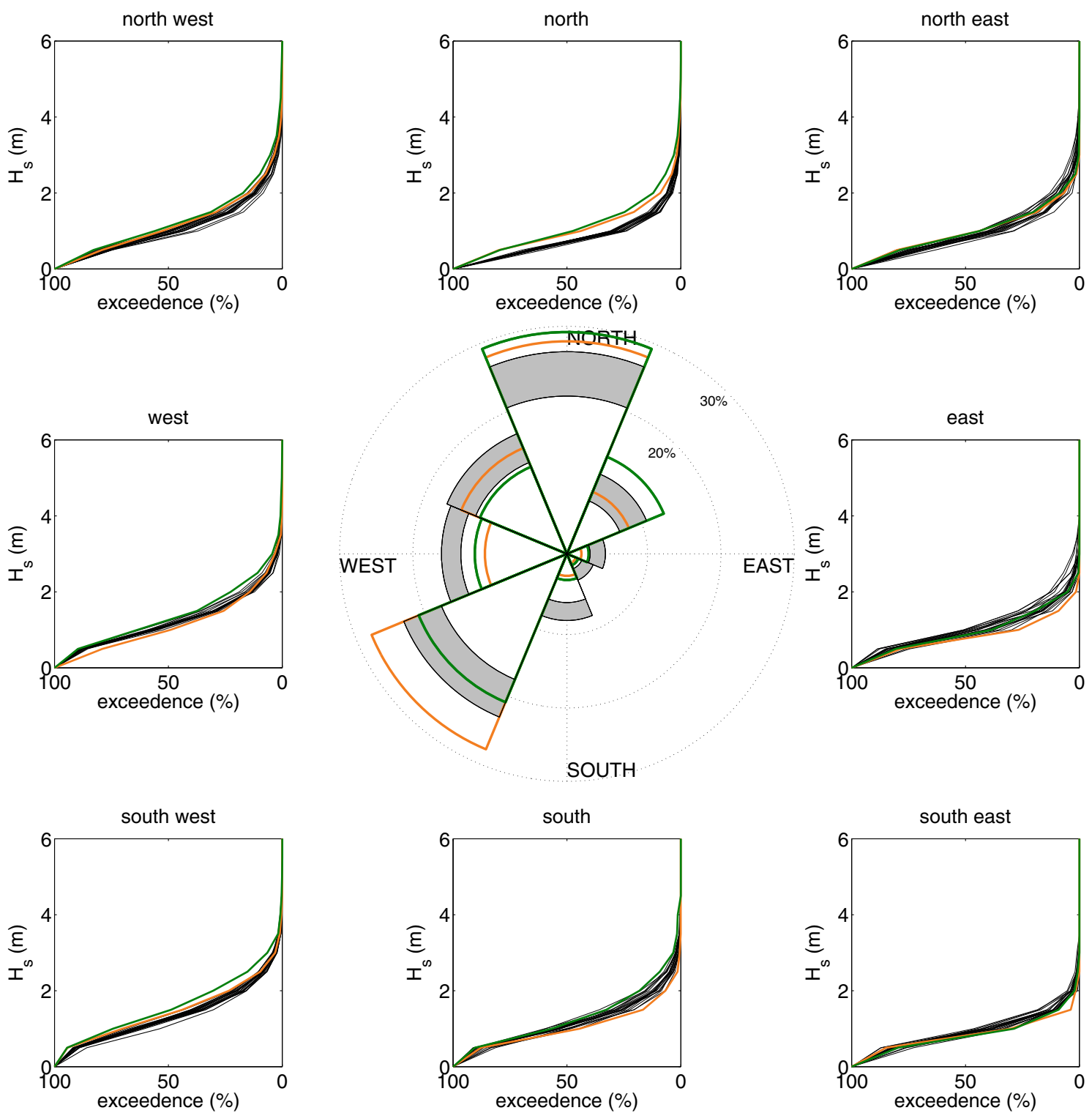

Fig. 5 The central plot shows the frequency of waves for $45^{\circ}$ wide direction classes at Eur for the period 2004-2009. Orange represents the observed directions and green represents the operational forecasted direction for the HIRLAM-NEDWAM calculations. In grey, the bandwidth of percentage of waves of the 17 ESSENCE-NEDWAM calculations is depicted. The surrounding plots show $H_{\mathrm{s}}$ exceedence curves for all eight direction classes. Colours are the same as for the central plot, and all the 17 ESSENCE-NEDWAM calculations are plotted individually in black amount of waves from the north (central plot of Fig. 5). Another factor contributing to the underestimation of the frequency of northerly wave direction may come from the fact that no swell can enter the NEDWAM domain from outside. Furthermore, the differences in frequency between the observed wave direction and the operational forecast for some directions are just as large as the difference in frequency between the ESSENCE-NEDWAM and the observed wave climatology. The amount of waves from south is furthermore slightly overestimated in the ESSENCE-NEDWAM climatology. Except from the waves from the north, the $H_{\mathrm{s}}$ exceedances are generally well reproduced by ESSENCE-NEDWAM (surrounding plots of Fig. 5), especially considering the underestimation of the wind speed.

In this analysis, it should be taken into account that a 6-year time period is compared, the true observed 2004-2009 wave climate and an in principle arbitrary 6 years from the ESSENCE ensemble. A 6-year time period is relatively short for climatological comparison. This might explain the discrepancy between the observed wave direction, the operational forecasted wave direction and the wave directions in the ESSENCE- 


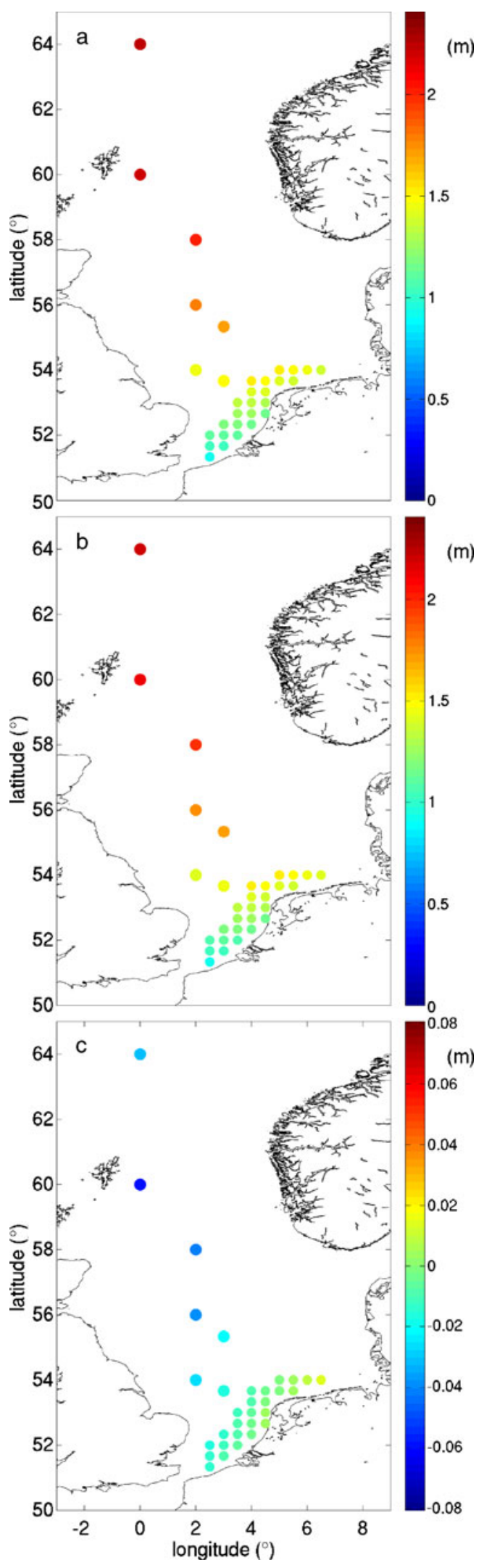

Fig. 6 The mean $H_{\mathrm{s}}$ for a period 1961-1990 and b 2071-2100. c The difference in mean annual $H_{\mathrm{s}}$ between the periods 20712100 and 1961-1990
NEDWAM climatology. We will mainly focus on the differences between the current wave climate and the future wave climate and thus perform a relative analysis. Given that the $H_{\mathrm{s}}-T_{\mathrm{m}}$ relation of the ESSENCENEDWAM combination is similar with the $H_{\mathrm{s}}-T_{\mathrm{m}}$ relation of observed wave climate, that $H_{\mathrm{s}}$ is reproduced well per direction and that the pattern of $\theta$ in the ESSENCE-NEDWAM climatology is similar with the observed $\theta$ pattern, we conclude that the ESSENCENEDWAM combination can be used to analyse the effect of climate change on differences in the wave climate in the North Sea.

\subsection{Wave climate analysis}

The changes in wave climate as a result of an enhanced greenhouse effect were studied by analysing NEDWAM output for a reference period 1961-1990 and a future period 2071-2100. The total effect of the increase in greenhouse gasses is expected to be largest when the increase is highest. Therefore, a 30year time slice at the end of the twenty-first century is chosen and compared with a 30-year time period in the reference climate. For both periods, the 3-hourly ESSENCE wind and sea level pressure input was kept constant for $3 \mathrm{~h}$, while NEDWAM calculated a new wave field every $10 \mathrm{~min}$. The wave characteristics $\left(H_{\mathrm{s}}\right.$, $\left.T_{\mathrm{m}}, \theta\right)$ were, however, saved every hour for a restricted number of grid locations (basically along the Dutch coast and seven points further north in the North Sea). From the available wave series, we examined whether the mean wave climate and annual maximum were projected to change. We then used, as detailed below, generalized extreme value (GEV) analysis to quantify any change in events with a probability of occurrence up to $1: 10,000$ years. The mean wave climate was calculated by taking, for each location and each time period, the average for all the 17 members. This results in an average $H_{\mathrm{s}}$ and $T_{\mathrm{m}}$ for each location and time period. The annual maximum conditions were selected by taking, per member, the annual maxima of $H_{\mathrm{s}}$ and $T_{\mathrm{m}}$. This results in $17 \times 30=510$ annual maxima for each location and time period. Mann-Whitney tests were applied to check whether the change in the annual maxima $H_{\mathrm{s}}$ and $T_{\mathrm{m}}$ was statistically significant at the 95\% confidence level (Von Storch and Zwiers 2001). We also analysed whether the incidence angle of the annual maximum $H_{\mathrm{s}}$ and $T_{\mathrm{m}}$ changed. This was done by calculating the percentage of annual maximum $H_{\mathrm{s}}$ or $T_{\mathrm{m}}$ events in $45^{\circ}$ bins.

The 510 annual maxima per location and time period are fitted to a GEV distribution (Coles 2001) that 
describes the statistical behaviour of block maxima, like annual maxima. It has three parameters, location $(\mu)$, scale $(\sigma)$ and shape $(\xi)$; for each parameter, we also estimated the $95 \%$ confidence interval. The probability density function (PDF) is given by

$f(x: \mu, \sigma, \xi)=\exp \left[-\left(1+\xi \frac{x-\mu}{\sigma}\right)^{-\frac{1}{\xi}}\right]$,

with $x$ being $H_{\mathrm{s}}$ or $T_{\mathrm{m}}$. The location of the peak of the PDF is determined by $\mu$, while $\sigma$ influences the width of the PDF. Furthermore, $\xi$ is an indication of the heaviness of the tail and determines the development of the return values. A higher $\xi$ results in more values in the tail of the PDF and therefore a heavier tail. Consequently, return values for a GEV with a higher $\xi$ are higher compared to a similar distribution with a lower $\xi$. The GEV parameters were used to calculate $t$ years return values as (for $H_{\mathrm{s}}$ and analogous for $\left.T_{\mathrm{m}}\right)$ :

$H_{s}(t: \mu, \sigma, \xi)=\mu-\left(\frac{\sigma}{\xi}\right)\left[1-\left(-\log \left(1-\frac{1}{t}\right)\right)\right]^{-\xi}$.

Fig. 7 The central plot shows the minimum and maximum percentage of waves from $45^{\circ}$ wide direction classes at Eur. Blue represents the ESSENCE-NEDWAM calculations for the period 1961-1990 and red for 2071-2100. The surrounding plots show $H_{\mathrm{S}}$ exceedence curves for all eight directions classes. The lines are the 17-member average for both periods; the standard deviations are not shown, since these hardly differ from the 17-member average. Colours are the same as for the central plot
The bandwidth of the return period is calculated using the $95 \%$ confidence interval estimates of the GEV parameters and Eq. 2.

\section{Results}

\subsection{Mean wave climate}

For the different locations in our study area, the mean $H_{\mathrm{s}}$ in the 1961-1990 period varies between 0.80 and $2 \mathrm{~m}$ (Fig. 6a), with the lower values near the coast and to the south. This pattern is also projected for the 2071-2100 period (Fig. 6b); the difference in mean $H_{\mathrm{s}}$ between both periods is virtually zero (Fig. 6c). The mean $T_{\mathrm{m}}$ ranges from 4.8 to $6.5 \mathrm{~s}$, with, as for $H_{\mathrm{s}}$, near-zero differences between both periods (not shown). Also, no change is projected in wave directions, as depicted for Eur in Fig. 7 as an example. In this figure, the percentage of waves from a certain direction can be seen as well as the exceedence frequency for $H_{\mathrm{s}}$ per direction for the two periods. It demonstrates that neither $\theta$ is projected to change nor do the wave heights from a certain direction differ. Other locations show similar results for $\theta$. Hence, the mean $H_{\mathrm{s}}, T_{\mathrm{m}}$ and $\theta$ is projected to remain the same in front of the
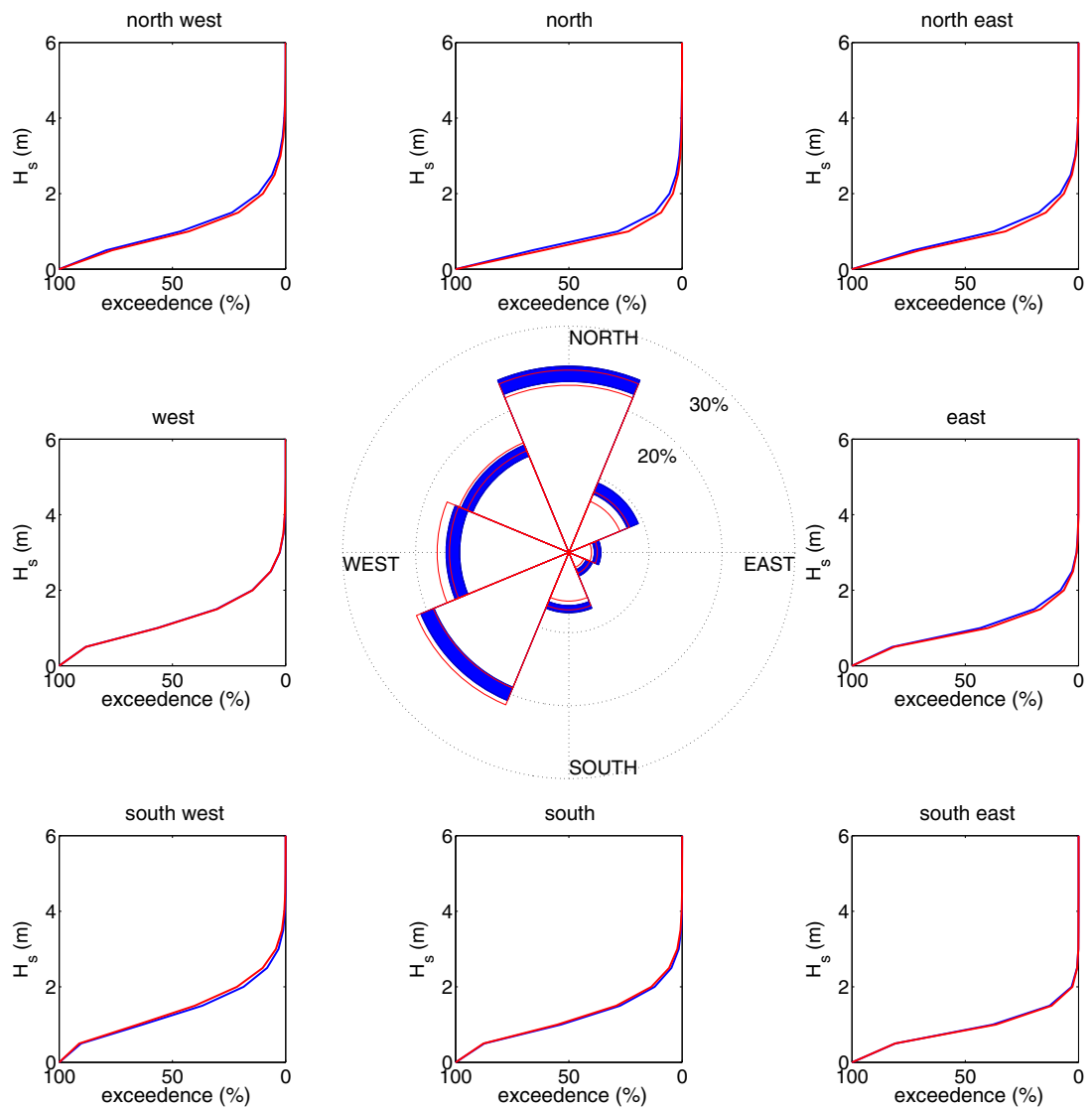
Dutch coast, according to the ESSENCE-NEDWAM combination and the SRES A1b scenario.

\subsection{Annual maximum wave climate}

The average annual $H_{\mathrm{s}}$ maximum strongly depends on the location as shown in Fig. 8a, b. Locations away from the coast have an average annual $H_{\mathrm{s}}$ maximum of $10 \mathrm{~m}$, while closer to the coast, the range of average annual $H_{\mathrm{s}}$ maxima is in the range of 4.5-7 m. During the period 2071-2100, the average annual $H_{\mathrm{s}}$ is projected to be significantly smaller at four offshore locations according the Mann-Whitney test. For these locations, a decrease in average annual $H_{\mathrm{s}}$ maximum between 0.2 and $0.5 \mathrm{~m}$ is projected, as can be seen in Fig. 8c. For locations near the Dutch coast, the difference in average annual $H_{\mathrm{s}}$ maximum is around zero. The results for the average annual $T_{\mathrm{m}}$ maximum are shown in Fig. 9. The average annual $T_{\mathrm{m}}$ maximum is projected to decrease by $0.3-0.6 \mathrm{~s}$ between $1961-1990$ and $2071-2100$ at all locations. This decrease is statistically significant at the 95\% confidence level.

The annual maxima for both $H_{\mathrm{s}}$ and $T_{\mathrm{m}}$ are coming less often from the north and north-west, as illustrated in the left column of Fig. 10. The annual $H_{\mathrm{s}}$ maxima from the north and north-west decrease by $40 \%$, while there is an increase in frequency of occurrence by $20 \%$ from the south-west at some locations. The shift in direction is even larger for the annual $T_{\mathrm{m}}$ maxima. In the period 1961-1990, the annual $T_{\mathrm{m}}$ maxima are coming from the north and north-western directions (Fig. 10, right column), while for the 2071-2100-period, the annual $T_{\mathrm{m}}$ maxima are projected to come up to $60 \%$ less often from these directions. The west and southwestern directions are now projected to dominate.

The directional change of the annual $H_{\mathrm{s}}$ and $T_{\mathrm{m}}$ maxima is in line with the results of Sterl et al. (2009) who showed that in the ESSENCE ensemble, wind speeds above $8 \mathrm{Bf}(17 \mathrm{~m} / \mathrm{s})$ come more often from the west and south-western directions in a future climate. These winds have a smaller fetch than winds from the north and north-western directions, causing a decrease in annual maximum $H_{\mathrm{s}}$ and especially $T_{\mathrm{m}}$. This change to more wind from the west at the end of this century is also projected in the studies of Wolf and Woolf (2006), Grabemann and Weisse (2008) and Debernard and Røed (2008).

\subsection{Wave climate for higher return periods}

The extreme value analysis is carried out for three locations: the Euro platform (Eur), a location north
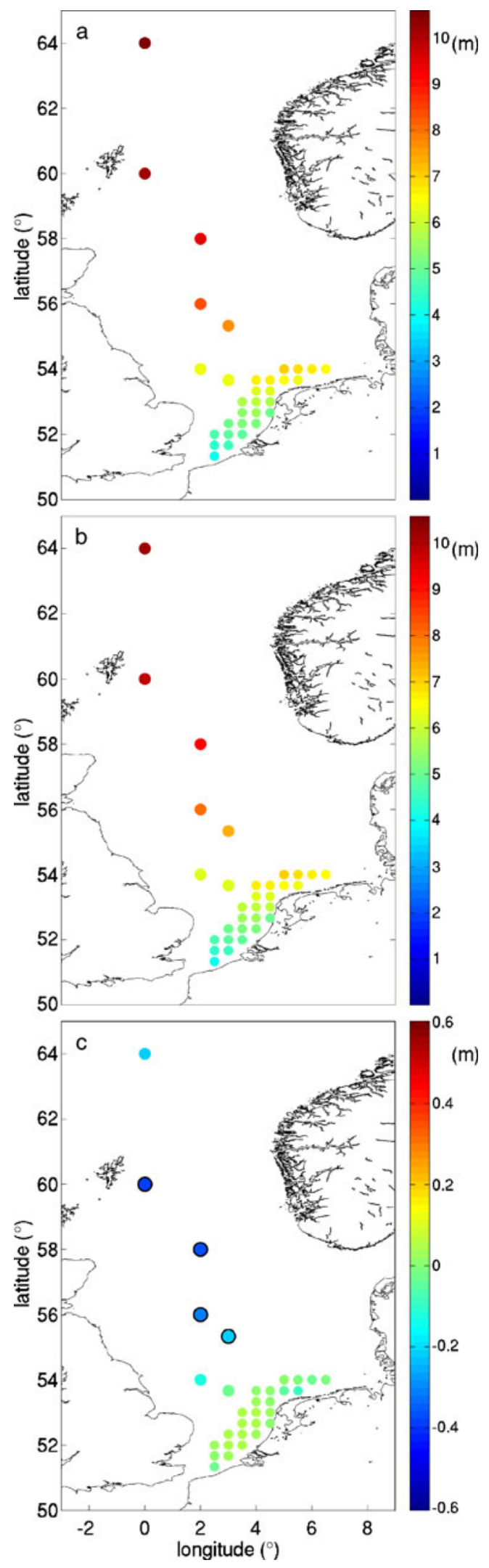

Fig. 8 Average annual $H_{\mathrm{s}}$ maximum for a period 1961-1990 and b 2071-2100. c The difference in average annual $H_{\mathrm{s}}$ maximum between periods 2071-2100 and 1961-1990. The change in $H_{\mathrm{s}}$ is significant for locations marked with a black circle 


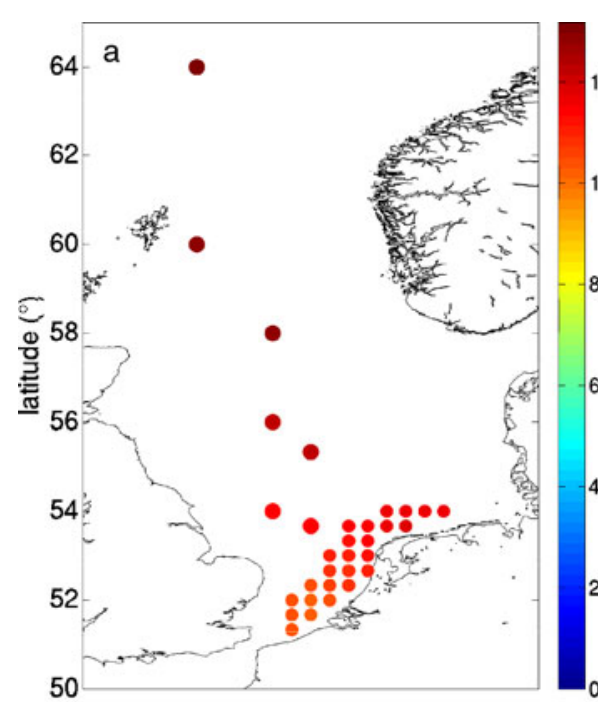

$2^{(s)}$
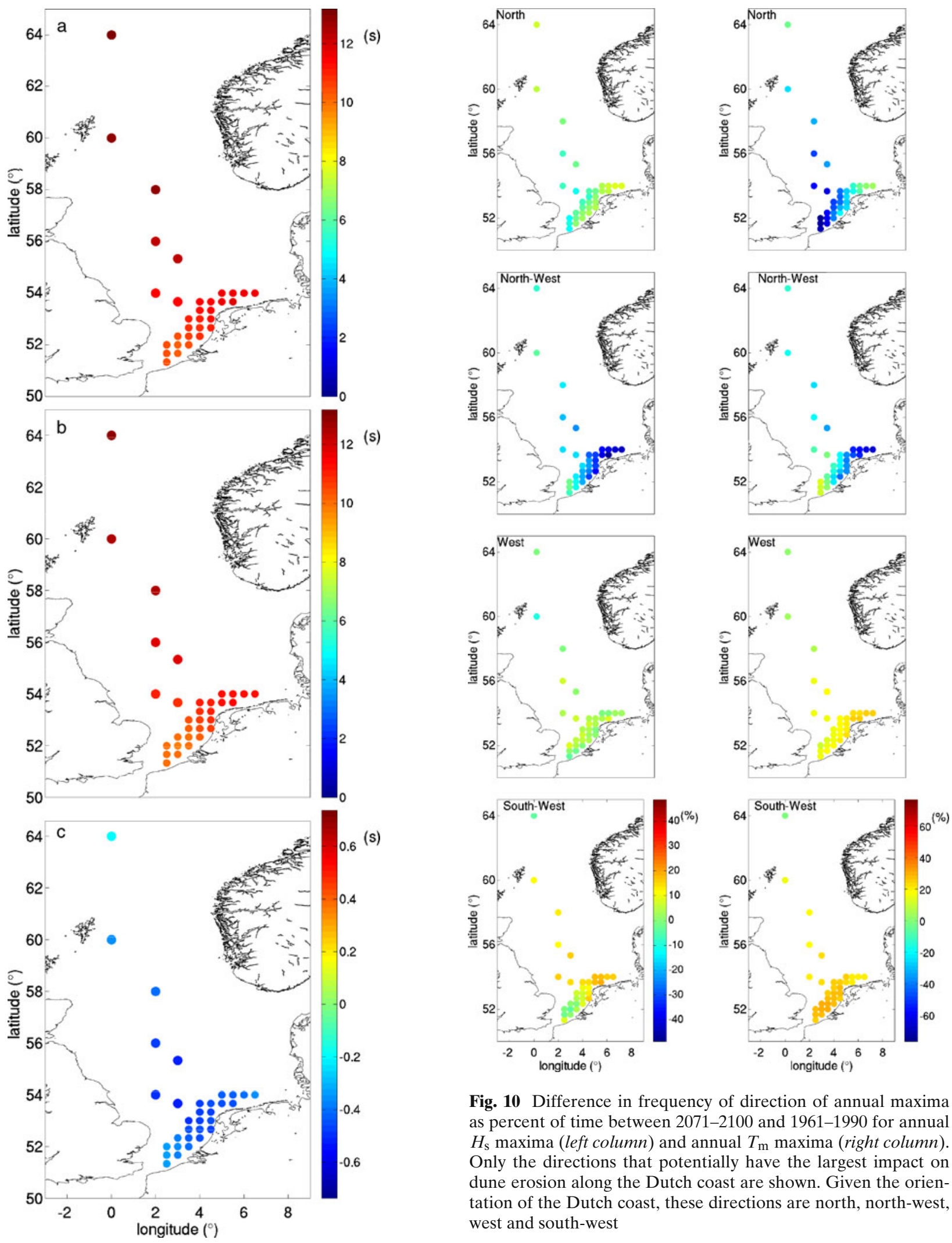

Fig. 10 Difference in frequency of direction of annual maxima as percent of time between 2071-2100 and 1961-1990 for annual $H_{\mathrm{s}}$ maxima (left column) and annual $T_{\mathrm{m}}$ maxima (right column). Only the directions that potentially have the largest impact on dune erosion along the Dutch coast are shown. Given the orientation of the Dutch coast, these directions are north, north-west, west and south-west

Fig. 9 As Fig. 8, now for annual $T_{\mathrm{m}}$ maximum. $\mathbf{c}$ The decline in $T_{\mathrm{m}}$ is significant for all locations

of the Wadden Sea (nWS) and a location in the North Sea (NS), Fig. 1. For NS, a decrease in average annual maxima was already observed in the previous section. 
Fig. 11 Left column: the GEV-PDF for annual $H_{\mathrm{s}}$ maximum, 1961-1990 (blue) and 2071-2100 (red), a NS, b nWS, c Eur. Right column: the return periods of annual $H_{\mathrm{s}}$ maximum $1961-1990$ (blue) and 2071-2100 (red), d NS, e nWS, f Eur
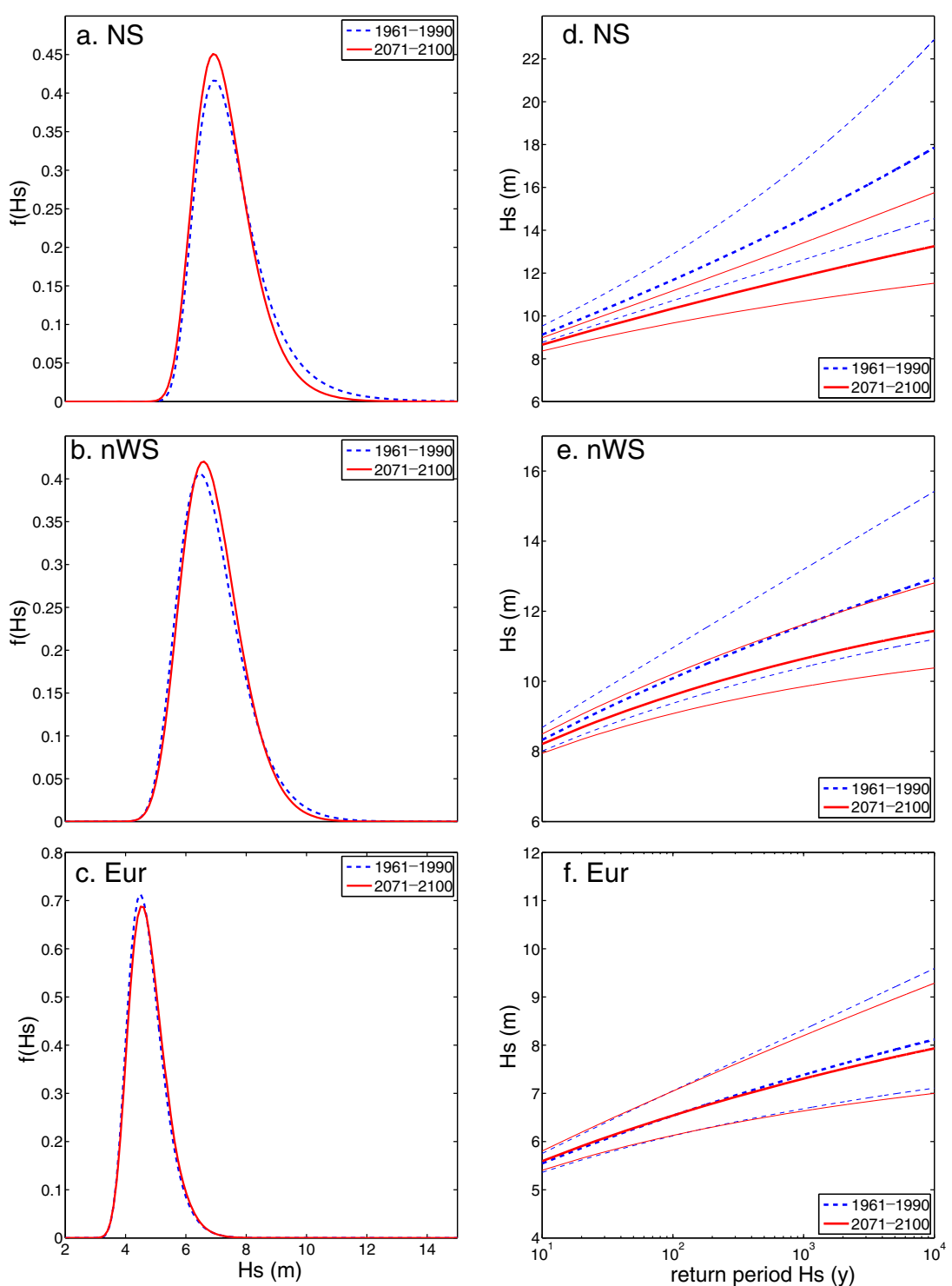

The GEV-PDF for NS (Fig. 11a) shows that the tail of the distribution is lighter as a result of a lower $\xi$. For Eur and for nWS, the GEV-PDFs of $H_{\mathrm{s}}$ remain approximately unaltered (Fig. 11b, c). The tail of the GEV-PDF at nWS for the period 2071-2100 is, however, slightly lighter, relative to the period 1961-1990, as indicated by a lower $\xi$. Fig. 11d-f shows the return wave heights for events with a return period of up to 10,000 years and illustrates how the differences in GEV-PDF translate to differences in the return periods. For Eur, where the GEV-PDF for the two periods has the same shape, the plots of the return heights lie almost on top of each other (Fig. 11f). For both nWS and NS, the lighter tail results in lower $H_{\mathrm{s}}$ for a return period of 10,000 years for the period 2071-2100 (Fig. 11d, e); however, this change is not significant at the $95 \%$ confidence level as indicated by the bandwidth of return heights.

The decrease in the annual $T_{\mathrm{m}}$ maximum (Fig. 9c) can also be observed in the GEV-PDFs of $T_{\mathrm{m}}$ as the peak of the distributions for the period 20712100 moves to lower $T_{\mathrm{m}}$. Moreover, the distributions become narrower, while a higher $\xi$ causes the tail of the GEV-PDFs for $T_{\mathrm{m}}$ to become heavier for the period 2071-2100. This is however hard to observe in Figs. $12 \mathrm{a}-\mathrm{c}$ because a lower $\mu$ shifts the entire distributions to lower values. The increased heaviness of the tail can, however, be seen when analysing events with high return periods, Fig. 12d, f. The combined effect of lower average annual values and a heavier tail of the GEV-PDF causes the 10,000-year return values for $T_{\mathrm{m}}$ to remain unaltered for the two periods. 
Fig. 12 As Fig. 11, now for annual $T_{\mathrm{m}}$ maximum
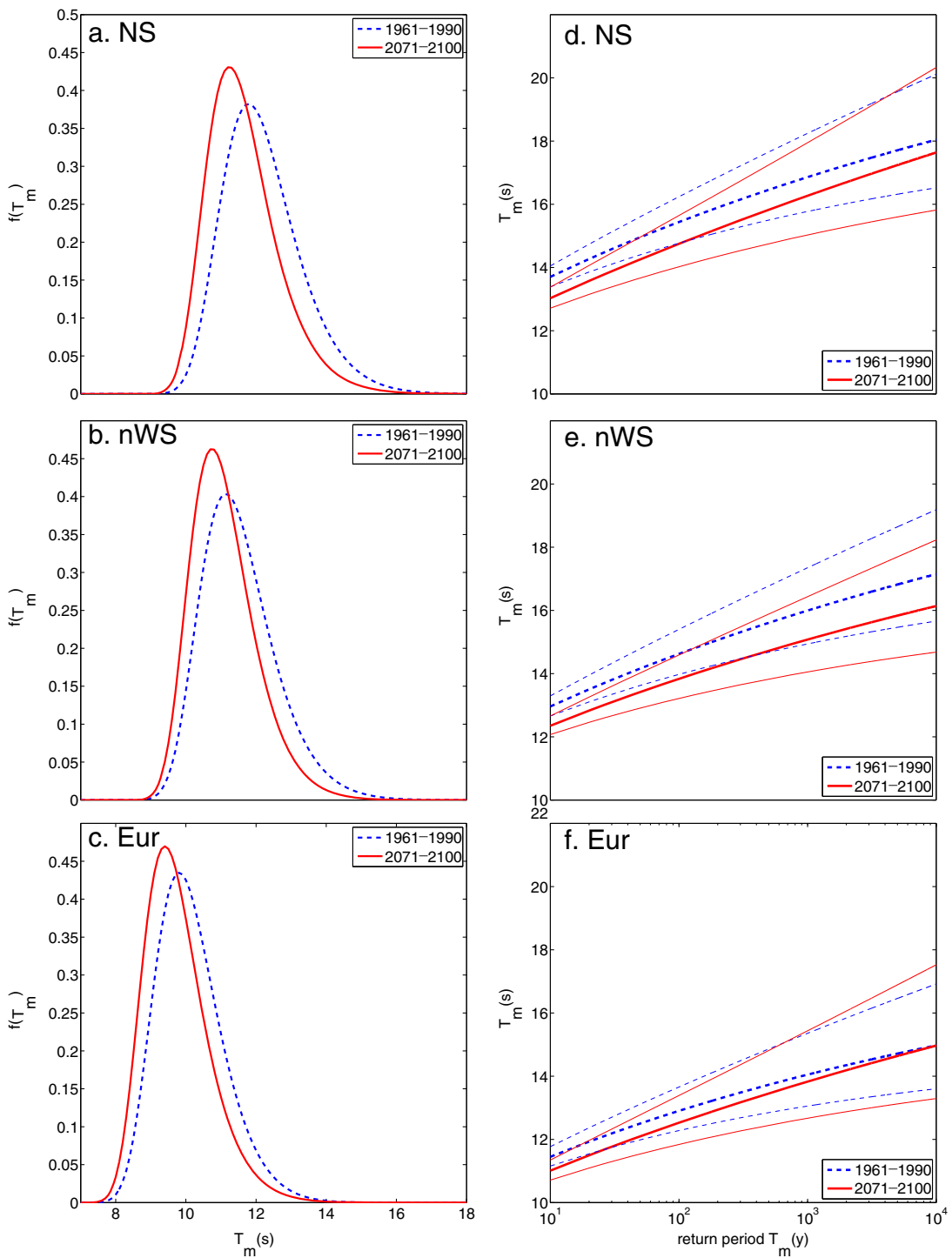

\section{Discussion}

We have focused on the effect of climate change on changes in the offshore (extreme) wave climate in front of the Dutch coast. As mentioned in Section 1, uncertainty exists in the climate scenarios, in the GCMs and because of the natural variability within the climate system. The 17-member ESSENCE ensemble allowed us to reduce the statistical uncertainty related to the internal variability. Therefore, we could analyse annual maximum events and explore events with a 10,000-year return period. This is a significant difference with earlier wave studies. For these extreme 10,000-year events, which are embedded in Dutch coastal policy, we did not find any statistically significant changes, since the change in return values was within the $95 \%$ confidence intervals. It is, however, certainly possible that different climate models and different emission scenarios lead to different results.

Annual maximum conditions are coming more often from west and south-west. Locations where the fetch is increasing when winds are coming from west and south-west, relative to north and north-west (e.g. the German Bight), might encounter higher extreme events as a result of climate change.

All results presented so far do not include the associate effect of climate change on sea level rise and with that on the wave climate. A rising sea level will increase the water depths in shallow areas. As a consequence, extreme $H_{\mathrm{s}}$ can increase (Chini et al. 2010), due to reduced energy dissipation by bottom friction or wave breaking. To investigate the effect of sea level rise on our study area, we re-run NEDWAM for one 20712100 ESSENCE member with an increased sea level of 
$1 \mathrm{~m}$. The effect on the annual $H_{\mathrm{s}}$ maximum is virtually zero in our study area. At the most nearshore locations, where the water depth is approximately $17 \mathrm{~m}$, a small increase is projected (maximum $2 \%$ ) during the most extreme events of the re-run member. It is therefore concluded that the water depths in our study area are generally too large for a 1-m sea level rise to impact the annual $H_{\mathrm{s}}$ maxima. However, even if climate change does not affect the offshore wave climate, dune erosion can still increase as a result of a higher sea level. Sea level rise will have two impacts on dune erosion. First, with a higher sea level, the level of wave attack on the dune will be higher. Second, a higher sea level can lead to larger water depths in front of the coast, causing waves propagating toward the coast in nearshore depths to lose less energy because of reduced bottom friction and breaking. The same offshore wave conditions with an increased sea level can, therefore, still increase dune erosion. The results of different climate models as well as the effect of sea level rise on the nearshore wave climate and hence dune erosion will be the focus points of our future work.

\section{Conclusions}

Dune erosion is an important aspect of coastal defence. One of the factors determining dune erosion is the wave climate. We investigate here the possible future changes in the offshore extreme wave climate in front of the Dutch coast by forcing the NEDWAM wave model with the output of the 17-member ESSENCE climate-change ensemble. The ESSENCE-NEDWAM combination generates a wave climate that is statistically consistent with measured $H_{\mathrm{s}}$ and $T_{\mathrm{m}}$ and has a similar pattern in $\theta$ as observed. With the SRES A1b scenario, the mean $H_{\mathrm{s}}$ and $T_{\mathrm{m}}$ in 2071-2100 does not differ with that in 1961-1990; also, the pattern in mean $\theta$ remains unaltered. In contrast to the mean wave climate, there are changes in the annual maximum wave climate. While the annual $H_{\mathrm{s}}$ maxima remain the same close to the Dutch coast, the annual $T_{\mathrm{m}}$ maxima are projected to decrease by $0.3-0.6 \mathrm{~s}$. Moreover, a shift is projected in the direction of the annual maximum conditions. More specifically, there is a projected decrease of $40 \%$ in annual $H_{\mathrm{s}}$ maxima from the north and northwest. The annual $T_{\mathrm{m}}$ maxima are coming $60 \%$ less often from the north and north-west and $30 \%$ of the time more often from the south-west. The change in direction of the annual maximum $T_{\mathrm{m}}$ and $H_{\mathrm{s}}$ is related to the shift in wind directions to the west and south-west for wind speeds above $8 \mathrm{Bf}(17 \mathrm{~m} / \mathrm{s})$. Fetch limitations for the west and south-west winds also explain the decrease in annual $T_{\mathrm{m}}$ maxima. $H_{\mathrm{s}}$ and $T_{\mathrm{m}}$ values with higher return periods, up to 10,000 years, are not projected to change significantly at the $95 \%$ confidence level for the period 2071-2100. We conclude that the offshore extreme wave conditions in the SRES A1b scenario using the ESSENCE ensemble do not change such that it influences the hydrodynamical boundary conditions for the Dutch coast.

Open Access This article is distributed under the terms of the Creative Commons Attribution License which permits any use, distribution, and reproduction in any medium, provided the original author(s) and the source are credited.

\section{References}

Bindoff NL, Willebrand J, Artale V, Cazenave A, Gregory J, Gulev S, Hanawa K, Le Qur C, Levitus S, Nojiri Y, Shum CK, D TL, Unnikrishnan A (2007) Observations: oceanic climate change and sea level. In: Climate change 2007: the physical science basis. Contribution of working group I to the fourth assessment report of the Intergovernmental Panel on Climate Change. Cambridge University Press, Cambridge

Bruun P (1962) Sea-level rise as a cause of shore erosion. J Waterw Harb Div 88:117-130

Burgers G (1990) A guide to the NEDWAM wave model. Koninklijk Nederlands Meteorologisch Instituut, De Bilt, WR-90-04

Cavaleri L (2009) Wave modeling missing the peaks. J Phys Oceanogr 39:2757, 22 pp. doi:10.1175/2009JPO4067.1

Chini N, Stansby P, Leake J, Wolf J, Roberts-Jones J, Lowe J (2010) The impact of sea level rise and climate change on inshore wave climate: a case study for East Anglia (UK). Coast Eng 57:973-984. doi:10.1016/j.coastaleng.2010.05.009

Coeveld EM, Den Heijer C, van de Graaff J, De Vroeg JH, Steetzel HJ (2005) The effect of wave period on dune erosion. Proceedings of 5th international conference on coastal dynamics. doi:10.1061/40855(214)19

Coles S (2001) An introduction to statistical modeling of extreme values. Springer-Verlag London Berlin Heidelberg

Debernard JB, Røed LP (2008) Future wind, wave and storm surge climate in the northern seas: a revisit. Tellus A 60:427438. doi:10.1111/j.1600-0870.2008.00312.x

Den Heijer C, Baart F, van Koningsveld M (2012) Assessment of dune failure along the Dutch coast using a fully probabilistic approach. Geomorphology 143-144: 95103. doi:10.1016/j.geomorph.2011.09.010

FitzGerald DM, Fenster MS, Argow BA, Buynevich IV (2008) Coastal impacts due to sea-level rise. Annu Rev Earth Planet Sci 36:601-647. doi:10.1146/annurev.earth.35.031306.140139

Van de Graaff J (1977) Dune erosion during a storm. Coast Eng 1:99-134

Grabemann I, Weisse R (2008) Climate change impact on extreme wave conditions in the North Sea: an ensemble study. Ocean Dyn 58:199-212. doi:10.1007/s10236-008-0141-x

Jungclaus JH, Keenlyside N, Botzet M, Haak H, Luo JJ, Latif M, Marotzke J, Mikolajewicz U, Roeckner E (2006) Ocean circulation and tropical variability in the coupled model ECHAM5/MPI-OM. J Climate 19:3952-3972

Kabat P, Fresco LO, Stive MJF, Veerman CP, van Alphen JSLJ, Parmet BWAH, Hazeleger W, Katsman CA 
(2009) Dutch coasts in transition. Nat Geosci 2:450-452. doi:10.1038/ngeo572

Komen GJ, Cavaleri L, Donelan M, Hasselmann S, Hasselmann K, Janssen PAEM (1994) Dynamics and modelling of ocean waves. Cambridge University Press, Cambridge

Lowe JA, Howard TP, Pardaens A, Tinker J, Holt J, Wakelin S, Milne G, Leake J, Wolf J, Horsburgh K, Reeder T, Jenkins G, Ridley J, Dye S, Bradley S (2009) Climate projections science report: marine and coastal projections. Met Office Hadley Centre, Exeter, UK

Mastenbroek C, Burgers G, Janssen PAEM (1993) The dynamical coupling of a wave model and a storm surge model through the atmospheric boundary layer. J Phys Oceanogr 23:1856-1866

Nicholls R, Cazenave A (2010) Sea-level rise and its impact on coastal zones. Science 328:1517-1520. doi:10.1126/ science. 1185782

Quartel S, Kroon A, Ruessink BG (2008) Seasonal accretion and erosion patterns of a microtidal sandy beach. Mar Geol 250:19-33. doi:10.1016/j.margeo.2007.11.003

Roelvink D, Reniers A, van Dongeren A, van Thiel de Vries J, McCall R, Lescinski J (2009) Modelling storm impacts on beaches, dunes and barrier islands. Coast Eng 56:1133-1152. doi:10.1016/j.coastaleng.2009.08.006

Ruessink BG, Jeuken MCJL (2002) Dunefoot dynamics along the Dutch coast. Earth Surf Processes Landf 27:1043-1056. doi:10.1002/esp.391

Steetzel HJ (2002) Effect van zwaardere golfcondities op duinenkust. Verkenning effect grotere golfhoogte enlangere golfperiode op mate duinafslag en veiligheid duinenkust. Alkyon Report A963. (In Dutch). Tech. rep., Alkyon
Sterl A, Severijns C, Dijkstra H, Hazeleger W, Van Oldenborgh GJ, Van den Broeke M, Burgers G, Van den Hurk B, Van Leeuwen PJ, Van Velthoven P (2008) When can we expect extremely high surface temperatures? Geophys Res Lett 35:L14,703. doi:10.1029/2008GL034071

Sterl A, Van den Brink H, De Vries H, Haarsma R, van Meijgaard R (2009) An ensemble study of extreme storm surge related water levels in the North Sea in a changing climate. Ocean Science 5:369

Van Gent MRA, van Thiel de Vries JSM, Coeveld EM, de Vroeg JH, van de Graaff $\mathbf{J}$ (2008) Large-scale dune erosion tests to study the influence of wave periods. Coast Eng 55:10411051. doi:10.1016/j.coastaleng.2008.04.003

Van Rijn LC (2009) Prediction of dune erosion due to storms. Coast Eng 56:441-457. doi:10.1016/j.coastaleng.2008.10.006

Vellinga P (1982) Beach and dune erosion during storm surges. Coast Eng 6:361-387

Vellinga P (1983) Predictive computational model for beach and dune erosion during storm surges. In: Proceedings coastal structures. ASCE, New York, pp 806-819

Vellinga P, Leatherman SP (1989) Sea level rise, consequences and policies. Clim Change 15:175-189. doi:10.1007/ BF00138851

Von Storch H, Zwiers FW (2001) Statistical analysis in climate research. Cambridge University Press, Cambridge

Wolf J, Woolf DK (2006) Waves and climate change in the northeast Atlantic. Geophys Res Lett 33:L06604. doi:10.1029/ 2005GL025113

Zhang K, Douglas BC, Leatherman SP (2004) Global warming and coastal erosion. Clim Change 64:41-58. doi:10.1023/B: CLIM.0000024690.32682.48 